\title{
An amperometric glucose-oxidase/poly(o-phenylenediamine) biosensor for monitoring brain extracellular glucose: in vivo characterisation in the striatum of freely-moving rats
}

\author{
John P. Lowry ${ }^{\mathrm{a}, *}$, Maddalena Miele ${ }^{\mathrm{b}}$, Robert D. O’Neill ${ }^{\mathrm{c}}$, Martyn G. Boutelle ${ }^{\mathrm{d}}$, \\ Marianne Fillenz ${ }^{\text {a }}$ \\ a University laboratory of Physiology, Parks Road, Oxford OX1 3PT, UK \\ ${ }^{\mathrm{b}}$ Institute of Pharmacology, University of Sassari, Viale San Pietro, Sassari 43/B-07100, Italy \\ ${ }^{\mathrm{c}}$ Department of Chemistry, University College Dublin, Belfield, Dublin 4, Ireland \\ d Department of Chemistry, King's College London, Strand, London WC2R 2LS, UK
}

Received 14 July 1997; received in revised form 22 September 1997; accepted 28 September 1997

\begin{abstract}
Amperometric glucose biosensors based on the immobilization of glucose oxidase (GOx) on Pt electrodes with electropolymerized $o$-phenylenediamine (PPD) were implanted in the right striatum of freely-moving rats. Carbon paste electrodes for the simultaneous monitoring of ascorbic acid (AA) and/or tissue $\mathrm{O}_{2}$ were implanted in the left striatum. A detailed in vivo characterization of the $\mathrm{Pt} / \mathrm{PPD} / \mathrm{GOx}$ signal was carried out using various pharmacological manipulations. Confirmation that the biosensor responded to changing glucose levels in brain extracellular fluid (ECF) was obtained by intraperitoneal (i.p.) injection of insulin that caused a decrease in the $\mathrm{Pt} / \mathrm{PPD} / \mathrm{GOx}$ current, and local administion of glucose $(1 \mathrm{mM})$ via an adjacent microdialysis probe that resulted in an increase in the biosensor current. An insulin induced increase in tissue $\mathrm{O}_{2}$ in the brain was also observed. Interference studies involved administering AA and subanaesthetic doses of ketamine i.p. Both resulted in increased extracellular AA levels with ketamine also causing an increase in $\mathrm{O}_{2}$. No significant change in the Pt/PPD/GOx current was observed in either case indicating that changes in $\mathrm{O}_{2}$ and $\mathrm{AA}$, the principal endogenous interferents, have minimal effect on the response of these first generation biosensors. Stability tests over a successive 5-day period revealed no significant change in sensitivity. These in vivo results suggest reliable glucose monitoring in brain ECF. (C) 1998 Elsevier Science B.V.
\end{abstract}

Keywords: Glucose biosensor; Carbon paste electrodes; Brain extracellular glucose; Ascorbic acid; Oxygen; Ketamine; Real-time monitoring; Freely-moving rats

\section{Introduction}

A number of biosensors have been developed for in vivo measurement of biologically important compounds which are either non-electroactive or only poorly electroactive at analytically useful potentials (Turner et al., 1987; Pfeiffer and Kerner, 1988; Pantano and Kuhr,

\footnotetext{
* Corresponding author. Present address: Department of Chemistry, University College Dublin, Belfield, Dublin 4, Ireland. Tel.: + 3531 7062274; fax: + 3531 7062127; e-mail: JLowry.@ OLLAMH.UCD.IE
}

1995). The most thoroughly investigated is the glucose biosensor incorporating the oxidoreductase enzyme, glucose oxidase (GOx). GOx, isolated from Aspergillus niger, has a high substrate specificity, a high turnover rate and excellent stability, that make it ideally suited for use in a biosensor (Wilson and Turner, 1992). This enzyme catalyses the oxidation of D-glucose in the presence of $\mathrm{O}_{2}$ producing $\mathrm{H}_{2} \mathrm{O}_{2}$ :

$$
\begin{aligned}
& \beta-D-\text { glucose }+G O x / F A D \\
& \rightarrow D-\text { glucono }-\delta-\text { lactone }+G O x / F A D H_{2}
\end{aligned}
$$


$\mathrm{GOx} / \mathrm{FADH}_{2}+\mathrm{O}_{2} \rightarrow \mathrm{GOx} / \mathrm{FAD}+\mathrm{H}_{2} \mathrm{O}_{2}$

where FAD is the oxidised form of the prosthetic group, flavin adenine dinucleotide.

Since the first report of a biosensor (for glucose) by Clark and Lyons (1962) there has been extensive research on the development and potential applications of biosensors, principally for subcutaneous or intravascular monitoring of glucose (Pfeiffer and Kerner, 1988). This is because of the importance of glucose monitoring in the disease diabetes mellitus and the fact that glucose determination in various body fluids, such as blood, plasma and urine, remains one of the most common analysis carried out in clinical laboratories. However, only a few such devices have been used in vivo in neurochemical studies. With the exception of a report by Boutelle et al. (1986) these have all been carried out in anaesthetized animals and have all involved amperometric enzyme-modified electrodes, predominantly for glucose (Lowry et al., 1994a; Silver and Ereciñska, 1994; Lowry and Fillenz, 1996; Netchiporouk et al., 1996; Lowry and Fillenz, 1997), with some recent reports for glutamate (Albery et al., 1992; Hu et al., 1994; Asai et al., 1996) and choline (Garguilo and Michael, 1993; Garguilo and Michael 1994). The small number of such reports reflects the numerous difficulties associated with performing direct neurochemical measurements in such a hostile and complex environment as brain extracellular fluid (ECF). In addition to the obvious immunological response to the implanted sensor, the ECF also contains surfactants (e.g. lipids), electrode poisons (e.g. proteins) and potential electrocatalysts (e.g. glutathione and ascorbic acid), all of which may affect the performance (e.g. the stability and response) of the implanted sensor (O’Neill, 1994). Other problems include restriction of mass-transport to the electrode surface by brain tissue, the biochemical effects of depletion of a chemical species from this matrix and the availability of suitable enzymes for the specific substrates of interest. Therefore, in order for a biosensor to operate reliably in brain ECF these and other factors such as size, linear calibration range and response time must be addressed in the design and development of the sensor.

Recently, the groups of Zambonin (Malitesta et al., 1990) and Yacynych (Sasso et al., 1990) have reported $\mathrm{H}_{2} \mathrm{O}_{2}$-detecting biosensors based on the immobilisation of $\mathrm{GOx}$ in electropolymerized poly(phenylenediamine) films on Pt electrodes with properties (e.g. interferencefree, high enzyme activity and low response time) indicating ideal suitability for detecting substrates in biological fluids. Several groups, including ourselves, have now used this technology to develop and characterise biosensors for a variety of substrates (Bartlett and Birkin, 1994; Dong, 1994; Lowry et al., 1994a; Friedemann et al., 1996). We have focused on the develop- ment of a glucose sensor for applications in the mammalian brain, as glucose is the primary energy source for the brain and a constant supply is essential to maintain normal cerebral function. A detailed in vitro characterisation has been carried out; this sensor, which utilises polymeric $o$-phenylenediamine (PPD), has a fast response time, linearity over the relevant concentration range, freedom from protein and lipid fouling and minimal interference from endogenous species such as AA and $\mathrm{O}_{2}$ over physiologically relevant concentration ranges (Lowry et al., 1994a,b; Lowry and O'Neill, 1994).

However, before any sensor can be used reliably in vivo it is necessary to perform a detailed in vivo characterisation to ensure the properties obtained in the in vitro environment are maintained in the more complex and hostile biological milieu. Thus, in the present study we have implanted the $\mathrm{Pt} / \mathrm{PPD} / \mathrm{GOx}$ biosensor in rat striatum and characterised the response in detail in awake freely-moving animals in order to provide unequivocal proof of what is being detected.

\section{Methodology}

\subsection{Chemicals and solutions}

The enzyme glucose oxidase from Aspergillus niger (EC 1.1.3.4, Grade I), was obtained from Boehringer Mannheim, East Sussex, UK. The $o$-phenylenediamine (free base), L-ascorbic acid (AA; A.C.S. reagent), ketamine (hydrochloride) and insulin (from bovine pancreas) were from Sigma Chemical, Dorset, UK. $\mathrm{D}(+)$-glucose (AnalaR grade) was obtained from $\mathrm{BDH}$ Laboratory Supplies, Poole, UK. The $\mathrm{NaCl}, \mathrm{KC}$, $\mathrm{NaH}_{2} \mathrm{PO}_{4}, \mathrm{NaOH}, \mathrm{MgCl}_{2}$ (all $\mathrm{BDH}$, AnalaR grade) and $\mathrm{CaCl}_{2}$ (Sigma) were used as supplied. Carbon paste was prepared by thoroughly mixing $2.83 \mathrm{~g}$ of carbon powder (UCP-1-M, Ultra Carbon, Bay City, MI) and $1.0 \mathrm{ml}$ of silicone oil (Aldrich Chemical, Dorset, UK, Catalogue No. 17563-3) (O’Neill et al., 1982).

Stock solutions of $1 \mathrm{M}$ glucose were prepared, left for $24 \mathrm{~h}$ at room temperature to allow equilibration of the anomers and then stored at $4^{\circ} \mathrm{C}$. All AA solutions were prepared just before use because of their gradual decomposition. Stock solutions of $100 \mathrm{mM}$ AA were prepared for in vitro calibrations. In in vivo experiments solutions of AA $(2 \mathrm{ml}, 2 \mathrm{~g} / \mathrm{kg})$, insulin $(1 \mathrm{ml}, 15$ $\mathrm{U} / \mathrm{kg})$, ketamine $(1 \mathrm{ml}, 50 \mathrm{mg} / \mathrm{kg})$ and glucose $(0.36 \mathrm{~g}$ in $2 \mathrm{ml}$ ) were administered intraperitoneally (i.p.). The $\mathrm{pH}$ of the AA solutions was adjusted to between 6.5 and 7.0 using $\mathrm{NaOH}$. Insulin solutions were prepared in a phosphate buffered saline (PBS) solution, $\mathrm{pH} 7.4$ (150 $\mathrm{mM} \mathrm{NaCl}, 40 \mathrm{mM} \mathrm{NaH} \mathrm{PO}_{4}$ and $40 \mathrm{mM} \mathrm{NaOH}$ ) and sonicated with heating for $\approx 5$ min to ensure complete dissolution. Glucose solutions used in in vivo experi- 
ments were prepared in artificial cerebrospinal fluid (aCSF: $147 \mathrm{mM} \mathrm{NaCl}, 4 \mathrm{mM} \mathrm{KCl}, 1.2 \mathrm{mM} \mathrm{CaCl}_{2}$ and $1 \mathrm{mM} \mathrm{MgCl}$ ) (de Boer et al., 1990) for microdialysis experiments $(1 \mathrm{mM})$ and in normal saline $(\mathrm{NaCl} 0.9 \%)$ for i.p. injections $(1 \mathrm{M})$. All solutions were prepared using deoxygenated doubly distilled deionised water.

\subsection{Working electrode preparation}

Glucose biosensors were based on the immobilization of GOx on Pt electrodes with the polymer PPD. Pt/ PPD/GOx disk electrodes were prepared from Tefloncoated platinum/iridium ( $\mathrm{Pt} / \mathrm{Ir}$ 90\%/10\%) wire $(125 \mu \mathrm{m}$ bare diameter, $160 \mu \mathrm{m}$ coated diameter (5T), Advent Research Materials, Suffolk, UK) following a previously reported procedure (Lowry et al., 1994a). Pt/ PPD/GOx cylinder electrodes were made from $5 \mathrm{~cm}$ lengths of the same $5 \mathrm{~T}$ wire. From each end $\approx 5 \mathrm{~mm}$ of the teflon insulation was carefully cut. The tip of the wire and the end of the teflon insulation at one end were then sealed under a microscope with epoxy glue to produce a $4 \mathrm{~mm}$ active length of bare wire. A gold electrical contact (Semat Technical, Herts, UK) was soldered to the other end. In order to ensure good GOx adsorption the exposed $4 \mathrm{~mm}$ of wire was then scored repeatedly with a scalpel blade. GOx was immobilised in PPD by potentiostatic electropolymenzation of the $o$-phenylenediamine monomer $(o-\mathrm{PD}, 300 \mathrm{mM}$ ) following a modified form of a previously reported procedure (Lowry et al., 1994a). Briefly, a deoxygenated solution of the monomer was prepared in PBS, pH 7.4. Electrodes were left standing in this $o$-PD solution for 60 min and then transferred to an enzyme solution ( $3 \mathrm{mg}$ $(850 \mathrm{U}) \mathrm{GOx}$ in $5 \mu 1 o$-PD). When the enzyme was visibly adsorbed (ca. 5-10 min, as indicated by a yellow coating on the wire), the electrodes were transferred to a plastic electrochemical cell (in house three-electrode design) containing $10 \mathrm{ml}$ of a freshly prepared $o$-PD solution. The reference (saturated calomel electrode, SCE) and auxiliary electrode (large Pt wire) were then connected and the electropolymerization procedure started by applying $+650 \mathrm{mV}$ to the $\mathrm{Pt} / \mathrm{PPD} / \mathrm{GOx}$ electrodes. The polymerization was terminated after 15 min and the Pt/PPD/GOx electrodes were then rinsed by immersion in PBS to remove loosely bound enzyme and unreacted monomer. When not in use all Pt/PPD/ GOx electrodes were stored in PBS at $4^{\circ} \mathrm{C}$. Carbon paste disk electrodes (CPEs) were also made from $5 \mathrm{~cm}$ lengths of $5 \mathrm{~T}$ teflon-coated $\mathrm{Pt} / \mathrm{Ir}$ wire following a previously described procedure (Lowry et al., 1997).

\subsection{Microdialysis probe construction}

Concentric microdialysis probes were constructed as described previously (Demestre et al., 1997). The length of the probe was $4 \mathrm{~mm}$ and the external diameter of the sampling region of the probe was $300 \mu \mathrm{m}$. Before implantation each probe was tested for leakages by perfusing aCSF at $2 \mu \mathrm{l} / \mathrm{min}$ using a CMA 100 microdialysis pump (CMA Microdialysis, Stockholm, Sweden).

\subsection{In vitro conditioning and characterisation of Pt/PPD/GOx electrodes}

Prior to implantation all $\mathrm{Pt} / \mathrm{PPD} / \mathrm{GOx}$ electrodes were preconditioned in vitro by continuous recording (see below) in $5 \mathrm{mM}$ glucose over a $10 \mathrm{~h}$ period. Electrodes were then calibrated in vitro for both glucose $(0-100 \mathrm{mM})$ and AA $(0-1 \mathrm{mM})$ to ensure selectivity and linearity of response of the sensor for glucose (Lowry and O'Neill, 1994). Calibrations were carried out in a standard three-electrode glass electrochemical cell. A SCE was used as the reference electrode and a large silver wire, isolated in a compartment containing PBS, served as the auxiliary electrode. To facilitate mixing, solutions were bubbled with air (glucose; RENA 102 air pump, RENA, France) or $\mathrm{N}_{2}$ (AA, BOC Gases, Guildford, UK) for ca. $10 \mathrm{~s}$ following the addition of each aliquot. The current was then measured when the solution was quiescent. The electrodes were held at a constant potential of $+700 \mathrm{mV}$, which is the value generally used for $\mathrm{H}_{2} \mathrm{O}_{2}$ detection (Lowry et al., 1994a). All calibrations were carried out at room temperature with the exception of a series of experimental measurements done at $37^{\circ} \mathrm{C}$. These were made by placing the cell on a temperature regulated hot plate $( \pm$ $2^{\circ} \mathrm{C}$, Sigma) and monitoring the solution temperature with a thermometer (Sigma) fixed permanently in the solution as near as possible to the biosensor. In experiments involving microdialysis, a characterized Pt/PPD/ GOx electrode was glued with epoxy to a microdialysis probe ca. $1 \mathrm{~h}$ prior to implantation so that the $4 \mathrm{~mm}$ active lengths of both probe and electrode were directly aligned. Care was taken to ensure that the probe and sensor were within $1 \mathrm{~mm}$ of each other.

\subsection{Surgical procedures}

Male Sprague-Dawley rats weighing 200-300 g were anaesthetised, following published guidelines (Wolfensohn and Lloyd, 1994), with a mixture of Hypnorm (Janssen Pharmaceuticals, Oxford, UK), Hypnovel (Roche Products, Herts, UK) and sterile water, mixed 1:1:2 and injected i.p. at a volume of $3.3 \mathrm{ml} / \mathrm{kg}$, as described previously (Fray et al., 1996; Lowry and Fillenz, 1997). Electrodes were then implanted following a previously described procedure (Lowry et al., 1997); CPEs were implanted in the left striatum (coordinates with the skull levelled between bregma and lambda, were: $\mathrm{A} / \mathrm{P}+1.0$ from bregma, $\mathrm{M} / \mathrm{L}-2.5$ and $\mathrm{D} / \mathrm{V}-5.0$ from dura (Paxinos and Watson, 1986)), $\mathrm{Pt} / \mathrm{PPD} / \mathrm{GOx}$ electrodes in the right striatum (coordi- 
nates: $\mathrm{A} / \mathrm{P}+1.0$ from bregma, $\mathrm{M} / \mathrm{L}+2.5$ and $\mathrm{D} / \mathrm{V}$ -8.5 from dura), and in experiments involving microdialysis the combined $\mathrm{Pt} / \mathrm{PPD} / \mathrm{GOx}$ electrode and microdialysis probe (perfused with aCSF at $2 \mu 1 / \mathrm{min}$ ) was implanted in the right striatum (coordinates: $\mathrm{A} / \mathrm{P}+1.0$ from bregma, $\mathrm{M} / \mathrm{L}+2.5$ and $\mathrm{D} / \mathrm{V}-8.5$ from dura). A reference electrode (8T Ag wire, $200 \mu \mathrm{m}$ bare diameter; Advent Research Materials) was placed in the cortex, an auxiliary electrode (8T Ag wire) placed between the skull and dura and an earth wire (8T Ag wire) attached to one of the support screws. The reference potential provided by the bare $\mathrm{Ag}$ wire in brain tissue is very similar to that of the SCE (O'Neill, 1993). The electrodes and probe were fixed to the skull with dental screws and dental acrylate (Associated Dental Products, Swindon, UK). Surgery typically lasted $40 \mathrm{~min}$ and anaesthesia was reversed by an i.p. injection of naloxone $(0.1 \mathrm{mg} / \mathrm{kg}$, Sigma). Post-operative analgesia was provided in the form of a single injection $(0.1 \mathrm{mg} / \mathrm{kg}$, s.c.) of Vetergesic (Reckitt and Colman Pharmaceuticals, Hull, UK) given immediately following the surgery. Animals were allowed to recover after surgery and were assessed for good health according to published guidelines (Morton and Griffiths, 1985) immediately after recovery from anaesthesia and at the beginning of each day. This work was carried out under licence in accordance with the Animals (Scientific Procedures) Act, 1986.

\subsection{Instrumentation and software}

A low-noise potentiostat (Biostat II, Electrochemical and Medical Systems, Newbury, UK) was used in all experiments. For constant potential amperometry (CPA) experiments, either a Macintosh IIx computer or a Mitac 486 PC was used with data acquisition carried out using National Instruments (NI, National Instruments, Austin, TX) multifunction data acquisition boards: NB-MIO-16X (Macintosh) and AT-MIO-16 (PC). Further noise reduction was achieved by averaging 75 (Mac) and 100 (PC) determinations to give one data point every $2 \mathrm{~s}$. For differential pulse amperometry (DPA) experiments, all data acquisition was carried out on a Mitac 486 PC with data sampling carried out at a rate of 250 determinations/pulse and averaged to give one data point/pulse (Lowry et al., 1996). A complete pulse sequence was carried out every 2 s. All experiments were carried out using in house developed software: PC (LabWindows, NI version 2.1); Macintosh (LabVIEW, NI version 2.2.1). All analysis was carried out using both in house developed software and the commercial packages Igor Pro 2.0 (WaveMetrics, OR) and Prism (GraphPad Software, CA). All data are presented as mean \pm SEM. The significance of differences observed was estimated using the Student's $t$-test (two-tailed) for paired observations (StatView, Abacus
Concepts, CA), or the repeated measures ANOVA with Tukey's posthoc test.

Animal motor activity was recorded using a radar based doppler shift motion detection unit (RS8960, RS Components, Northants, UK; $10.7 \mathrm{GHz}$, wavelength $2.8 \mathrm{~cm})$ connected to the Mitac PC via the NI ATMIO-16 data acquisition board. The meter was modified with a closed end metal wave guide so that ambulatory movements, grooming, feeding and drinking registered, but not lesser movements such as breathing (Berners, 1996).

\subsection{Experimental conditions}

Rats were housed in large plastic bowls (diameter ca. $50 \mathrm{~cm}$ ), in a windowless room under a $12 \mathrm{~h}$ light/dark cycle, lights coming on at 8 a.m., with free access to water. Food was available ad libitum except for experiments involving insulin where animals were fasted for $24 \mathrm{~h}$ prior to administration. All experiments were carried out with the animal in its home bowl. Implanted electrodes were connected to the potentiostat through a six-pin teflon socket and a flexible screened six core cable which was mounted through a swivel above the rat's head (Semat Technical) at least $60 \mathrm{~min}$ prior to the start of the first experiment each day. This arrangement allowed free movement of the animal. Once the background current for the $\mathrm{Pt} / \mathrm{PPD} / \mathrm{GOx}$ electrode had stabilised (typically $30-45 \mathrm{~min}$ ) experiments were begun. The $\mathrm{O}_{2}$ and AA signal from the CPE stabilised within 5-10 min. All signals were recorded at $2 \mathrm{~s}$ intervals. At the end of each day the animals were disconnected from the recording equipment.

\subsection{Voltammetric techniques in vivo}

As with in vitro experiments, CPA at $+700 \mathrm{mV}$ (versus implanted $\mathrm{Ag}$ reference electrode) was used for $\mathrm{H}_{2} \mathrm{O}_{2}$ oxidation at the $\mathrm{Pt} / \mathrm{PPD} / \mathrm{GOx}$ electrodes in vivo. Changes in $\mathrm{O}_{2}$ and AA at implanted CPEs were monitored using either DPA or CPA. The DPA technique allows the simultaneous monitoring of both species. For $\mathrm{O}_{2}$ reduction, two equally sized cathodic pulses were applied, the first from a resting potential at -150 to $-350 \mathrm{mV}$ that corresponds to the foot of the reduction wave for $\mathrm{O}_{2}$ at lipid-modified CPEs and the second from -350 to $-550 \mathrm{mV}$ that corresponds to the peak of the reduction wave. Following the same criterion, equally sized anodic pulses were then applied from -150 to $+50 \mathrm{mV}$ and from +50 to $+250 \mathrm{mV}$ for AA oxidation. The difference in the current $(\Delta \mathrm{I})$ sampled during these respective pulse pairs was calculated and changes in $\Delta \mathrm{I}$ used as a measure of changes in $\mathrm{O}_{2}$ and AA that have been shown to be interference free (Lowry et al., 1996). In experiments involving $\mathrm{CPA}, \mathrm{O}_{2}$ was detected by holding the implanted CPE at 
the reduction potential of $-550 \mathrm{mV}$ (Lowry et al., 1997). The potential for AA detection was chosen as $+250 \mathrm{mV}$, which is just above the peak potential for AA oxidation but below that for the onset of the oxidation of other neurochemical species at implanted CPEs (Boutelle et al., 1989). Post in vivo calibrations for AA and $\mathrm{O}_{2}$ were carried out using the two techniques. Calibrations for dissolved $\mathrm{O}_{2}$ were carried out in $\mathrm{N}_{2}$ purged, air-saturated and $\mathrm{O}_{2}$-saturated solutions where the concentrations of solution $\mathrm{O}_{2}$ were taken as 0, 200 (Bourdillon et al., 1982; Zhang and Wilson, 1993) and $1250 \mu \mathrm{M}$ (Bourdillon et al., 1982), respectively. AA calibrations were carried out in the range $0-1 \mathrm{mM}$.

\section{Results and discussion}

\subsection{Effect of temperature on biosensor response}

Temperature-dependence studies at GOx-modified electrodes in phosphate buffer have indicated that the glucose response may increase by between 20 (Shaolin et al., 1991) and $60 \%$ (Fortier et al., 1990) in the range $25-37^{\circ} \mathrm{C}$. Thus, before performing experiments in vivo we first examined the effect of temperature on the $\mathrm{Pt} / \mathrm{PPD} / \mathrm{GOx}$ signal since all our previous in vitro experiments had been carried out at a thermostatically controlled temperature of $25.0 \pm 0.5^{\circ} \mathrm{C}$ (Lowry et al., 1994a; Lowry and O’Neill, 1994). Glucose calibrations were therefore carried out at room $\left(22.5 \pm 0.2^{\circ} \mathrm{C}\right)$ and near physiological $\left(37.6 \pm 0.2^{\circ} \mathrm{C}\right)$ temperatures in the range $0-100 \mathrm{mM}$. The $\mathrm{V}_{\max }$, calculated using a modified Michaelis-Menten (Hill-type) equation (Lowry et al., 1994a), $100 \mathrm{mM}$ glucose and $1 \mathrm{mM}$ glucose responses were similar at both temperatures $(n=3)$ : $\mathrm{V}_{\max }, 127 \pm 32 \mathrm{nA}\left(22^{\circ} \mathrm{C}\right)$ and $127 \pm 37 \mathrm{nA}\left(37^{\circ} \mathrm{C}\right.$; $p>0.97) ; 100 \mathrm{mM}, 122 \pm 30 \mathrm{nA}\left(22^{\circ} \mathrm{C}\right)$ and $117 \pm 32$ $\mathrm{nA}\left(37^{\circ} \mathrm{C} ; p>0.50\right) ; 1 \mathrm{mM}, 4.4 \pm 1.8 \mathrm{nA}\left(22^{\circ} \mathrm{C}\right)$ and $6.7 \pm 0.6 \mathrm{nA}\left(37^{\circ} \mathrm{C} ; p>0.42\right)$; indicating that the change in temperature from in vitro to in vivo conditions will have minimal effect on the response of the biosensor. This property may be due to the nature of the PPD film which is a highly insulating thin (ca. 10 $\mathrm{nm}$ ) polymer immobilising the GOx (diameter $8.6 \mathrm{~nm}$ ) close to the electrode surface and acting as an efficient diffiusion barrier preventing glucose penetrating the film but not preventing it reaching the active site and producing $\mathrm{H}_{2} \mathrm{O}_{2}$ (Sasso et al., 1990). The detection limit, defined as the analyte (glucose) concentration yielding a signal equal to three times the standard deviation of the background current, for these $4 \mathrm{~mm}$ cylinder biosensors was calculated as $3.53 \pm 0.48 \mu \mathrm{M}$ $(n=4)$.

\subsection{Effect of insulin on biosensor response in vivo}

In order to demonstrate that $\mathrm{Pt} / \mathrm{PPD} / \mathrm{GOx}$ sensors respond to changes in glucose in brain ECF we began the in vivo characterization by examining the effect of insulin on the in vivo response. Insulin, which lowers plasma glucose levels (Chen and Steger, 1993) and has also been reported to lower brain ECF levels (Bhattacharya and Saraswati 1991), was injected i.p. (15 $\mathrm{U} / \mathrm{kg}$ ) into freely-moving fasted rats implanted with a glucose biosensor in the right striatum and a CPE in the left striatum. The mean baseline glucose current decreased by $0.6 \pm 0.1 \mathrm{nA}(n=4 ; p<0.01) 41 \pm 11 \mathrm{~min}$ after injection, representing a decrease in response of $14 \pm 4 \%$ (Fig. 1, top). This period of minimum glucose current lasted approximately $22 \pm 10$ min during which the animals were inactive but responsive to external stimuli suggesting that this dose of insulin did not produce hypoglycaemic coma. There was then a gradual return to baseline values or above during which the animals ingested food and resumed activity.
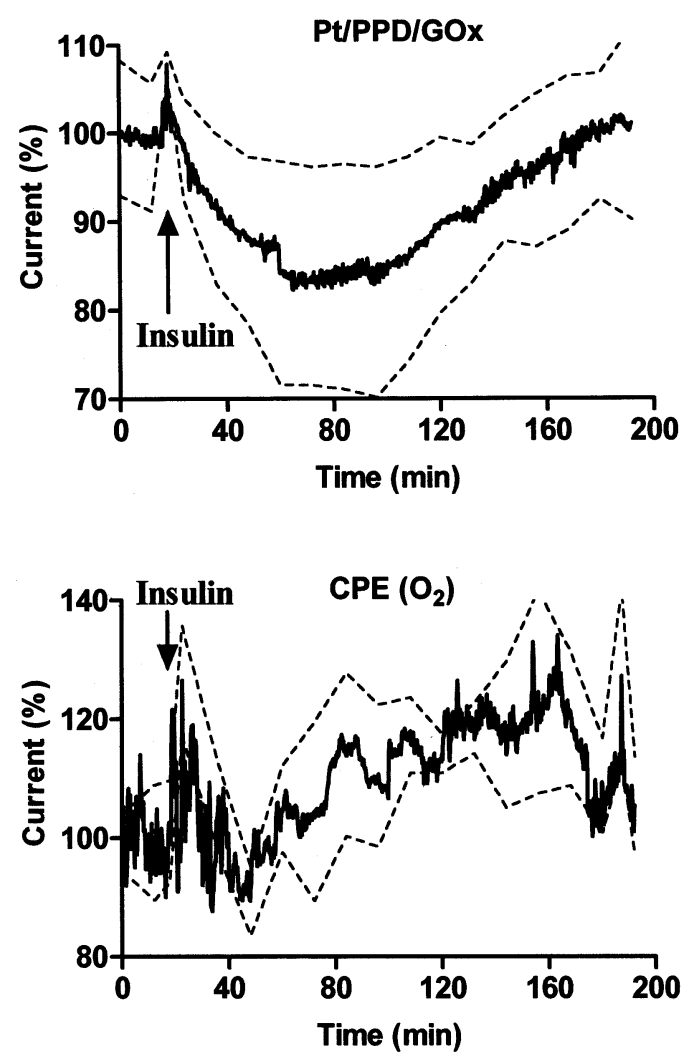

Fig. 1. The effect of intraperitoneal injection of insulin $(1 \mathrm{ml}, 15$ $\mathrm{U} / \mathrm{kg}$ ) on the $\mathrm{Pt} / \mathrm{PPD} / \mathrm{GOx}$ (top) and carbon paste electrode (CPE) $\mathrm{O}_{2}$ (bottom) signals recorded simultaneously with bilaterally implanted sensors in the striatum of freely-moving rats. The tissue $\mathrm{O}_{2}$ levels at the CPEs were monitored using both differential pulse amperometry and constant potential amperometry. Data $(n=4)$ are normalised with the basal level before injection taken as $100 \%$. The hashed lines represent the SEM which is plotted at $12 \mathrm{~min}$ intervals for clarity. Changes in response expressed in nanoamperes of current are given in the text. See Section 3.2. 
Tissue $\mathrm{O}_{2}$ levels were recorded simultaneously at the implanted CPEs using both DPA and CPA. Injection of insulin caused a maximum increase in cathodic current of $18 \pm 7 \mathrm{nA}(n=4 ; p<0.05)$ above baseline at $63 \pm 22 \mathrm{~min}$. We have previously shown that both these techniques can be used to monitor changes in tissue $\mathrm{O}_{2}$ in vivo during neuronal activation (Lowry et al., 1997). However, typical baseline currents observed in vivo for the DPA and $\mathrm{CPA} \mathrm{O}_{2}$ signals are $-748 \pm 18 \mathrm{nA}$ $(n=3)$ and $-49 \pm 4 \mathrm{nA}(n=3)$, respectively. It is thus not possible to calculate a percentage change in $\mathrm{O}_{2}$ concentration from the in vivo signal. However, post in vivo calibrations of CPEs indicate that despite such background currents there is no significant difference $(p>0.95, n=5)$ in the sensitivity for $\mathrm{O}_{2}$ using the two techniques: $-378 \pm 136, n=5$ (DPA) and $-371 \pm$ $100, n=5$ (CPA). Therefore, using these calibrations the increase in $\mathrm{O}_{2}$ observed with insulin corresponds to a change in concentration of $68 \pm 23 \mu \mathrm{M}, n=4$ (Fig. 1, bottom), which if one assumes a basal ECF concentration of $50 \mu \mathrm{M}$ (Zimmerman and Wightman, 1991) corresponds to an approximate doubling of the ECF level.

These results suggest that $\mathrm{Pt} / \mathrm{PPD} / \mathrm{GOx}$ sensors respond to changing glucose levels in the ECF. A fall in brain glucose in animals given insulin has previously been reported by several groups using GOx-modified microelectrochemical sensors. Boutelle et al. (1986) observed a similar decrease of $\approx 10 \%$ in awake freelymoving animals with the same dose of insulin. Silver and Ereciñska (1994) and Netchiporouk et al. (1996) however both observed decreases of $\approx 80-90 \%$ of control. This difference may be due to a combination of factors including the use of higher doses of insulin (25 and $40 \mathrm{U} / \mathrm{kg}$, respectively) and the fact that both these reports involved acute experiments on anaesthetized animals where a decrease in the extracellular concentration of glucose would be expected (Fillenz and Lowry, 1997). An increase in brain $\mathrm{O}_{2}$ levels accompanying an insulin induced fall in brain glucose has also been reported by Silver and Ereciñska (1994). The different time courses of changes in glucose and oxygen observed with insulin suggest that changing $\mathrm{O}_{2}$ levels in vivo do not influence the $\mathrm{Pt} / \mathrm{PPD} / \mathrm{GOx}$ signal supporting our previously published in vitro work on $\mathrm{O}_{2}$ interference (Lowry et al., 1994b). A more detailed investigation of this type of interference is presented below (see Section 3.4).

\subsection{Effect of glucose on biosensor response in vivo}

Further evidence that $\mathrm{Pt} / \mathrm{PPD} / \mathrm{GOx}$ sensors respond to glucose changes in the ECF may be obtained by increasing the extracellular concentration of glucose. This has previously been achieved using intraperitoneal injections of glucose (Silver and Ereciñska, 1994;
Netchiporouk et al., 1996) or the hormone glucagon (Netchiporouk et al., 1996), which counterbalances the action of insulin in that it regulates the concentration of blood glucose by increasing the break down of glycogen stores (Stryer, 1988). However, the effect of glucagon was found to produce only a small rise in ECF glucose before triggering insulin release and a subsequent fall in glucose to below basal levels (Netchiporouk et al., 1996).

We examined the effect of injecting glucose $(0.36 \mathrm{~g}$ in $2 \mathrm{ml}$ i.p.) on the in vivo response of the implanted biosensor in awake normoglycemic animals and found no significant difference $(p>0.46, n=3)$ in the signal before $(12.5 \pm 1.1 \mathrm{nA}, n=3)$ and after $(12.8 \pm 0.7 \mathrm{nA}$, $n=3$ ) injection. This is contrary to previous reports where injection of similar doses resulted in increased glucose levels (Silver and Ereciñska, 1994; Netchiporouk et al., 1996). However, the animals used in those experiments may have been more sensitive to hyperglycemia since one of the reports involved injections during insulin induced hypoglycemia (Netchiporouk et al., 1996) and both involved anaesthetics which lower ECF glucose (Fillenz and Lowry, 1997). In the only other report involving awake freelymoving animals glucose was administered by infiusion through a cannula placed next to the implanted sensor (Boutelle et al., 1986) because i.p. injections failed to produce an increase in the extracellular concentration (Boutelle, M.G., personal communication). This and our similar observation, agree with results where elevation of plasma glucose levels from 8 to $50 \mathrm{mM}$ resulted in only modest increases in CSF glucose, suggesting control and carrier saturation (DiMattio and Streitman, 1988). Therefore, in order to increase ECF glucose levels in the local environment of the $\mathrm{Pt} / \mathrm{PPD} / \mathrm{GOx}$ sensor a microdialysis probe was combined with the biosensor before implantation into the striatum. The reason for this was two-fold in that not only does it enable direct administration of glucose in the present experiments it will also allow local infusion of drugs (e.g. propranolol (Fray et al., 1996)) for future studies of brain energy metabolism. Perfusion of a $1 \mathrm{mM}$ glucose solution through the dialysis probe at a flow rate of $2 \mu \mathrm{l} / \mathrm{min}$ produced a maximum increase in current of $2.3 \pm 0.6 \mathrm{nA}(n=5 ; p<0.02)$ from a mean baseline of $17.0 \pm 3.7 \mathrm{nA}$. This represents a mean increase of $14 \pm 3 \%$ and provides corroborating evidence that $\mathrm{Pt} / \mathrm{PPD} / \mathrm{GOx}$ sensors respond to changing glucose levels in the ECF. A typical example of the effect of such a perfusion on the current from an adjacent $\mathrm{Pt} / \mathrm{PPD} / \mathrm{GOx}$ sensor is shown in Fig. 2.

\subsection{Effect of oxygen on biosensor response in vivo}

$\mathrm{Pt} / \mathrm{PPD} / \mathrm{GOx}$ sensors are 'first generation' devices since they detect glucose by oxidising $\mathrm{H}_{2} \mathrm{O}_{2}$ formed 


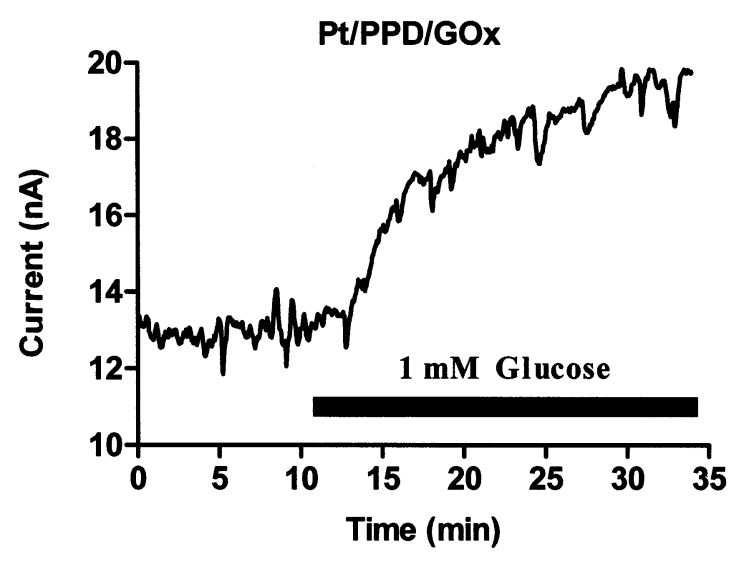

Fig. 2. A typical example of the effect of perfusing glucose $(1 \mathrm{mM}$ in aCSF) through a microdialysis probe on the current recorded with an adjacent $\mathrm{Pt} / \mathrm{PPD} / \mathrm{GOx}$ sensor. The combined probe and sensor were implanted in the right striatum of a freely-moving rat. The dark bar represents the period of perfusion. See Section 3.3.

from the reaction of $\mathrm{O}_{2}$, the natural cosubstrate for $\mathrm{GOx}$, with the reduced form of the enzyme (GOx/ $\left.\mathrm{FADH}_{2}\right)$ which is generated by reaction with glucose (see reactions 1 and 2 above). We have previously demonstrated in vitro that these biosensors respond to glucose in $\mathrm{O}_{2}$-depleted $\left(\mathrm{N}_{2}\right.$-saturated) solutions with a sensitivity similar to that of air-saturated media (200 $\mu \mathrm{M} \mathrm{O}_{2}$ ) (Bourdillon et al., 1982; Zhang and Wilson, 1993), suggesting that in brain tissue where the range of $\mathrm{O}_{2}$ tension is $5-50 \mu \mathrm{M}$ (Feng et al., 1988; Zimmerman and Wightman, 1991), glucose monitoring should be free of $\mathrm{O}_{2}$ interference (Lowry et al., 1994b).

To test the effect of changing $\mathrm{O}_{2}$ levels on the response of the glucose biosensor in vivo we simultaneously recorded both $\mathrm{Pt} / \mathrm{PPD} / \mathrm{GOx}$ and $\mathrm{CPE} \mathrm{O}_{2}$ signals before and after administration of the anaesthetic ketamine. Ketamine is a non-competitive antagonist of the glutamatergic $N$-methyl-D-aspartate (NMDA) receptor (Jantzen, 1994; Lahti et al., 1995) which causes an initial decrease in striatal tissue $\mathrm{O}_{2}$ and regional cerebral blood flow ( $\mathrm{rCBF}$ ), followed, on recovery, by an increase in both variables to levels above basal, which is accompanied by a period of intense motor activity predominated by stereotypic head movements (Lowry, J.P., unpublished observations). A typical example of the effect of a subanaesthetic ketamine injection $(50 \mathrm{mg} / \mathrm{kg})$ on the $\mathrm{Pt} / \mathrm{PPD} / \mathrm{GOx}$ and $\mathrm{O}_{2}(\mathrm{CPE})$ signals recorded simultaneously in the striatum of a freely-moving rat is shown in Fig. 3, together with a record of the motor activity for the same period. In three experiments the average $\mathrm{O}_{2}$ current recorded using DPA increased to a maximum of $79 \pm 18 \mathrm{nA}(n=3$, $p<0.05$ ) above baseline $3.2 \pm 0.8 \mathrm{~min}$ following injection and was still elevated at $42 \pm 6 \mathrm{~min}(77 \pm 25 \mathrm{nA})$, whereas there was no significant change in the response of the glucose biosensor over the same period: $4.7 \pm 0.3$ $\mathrm{nA}$ (baseline), $4.7 \pm 0.3 \mathrm{nA}(3.2 \pm 0.8 \mathrm{~min} ; p>0.6)$ and
$4.5 \pm 0.2 \mathrm{nA}(42 \pm 6 \mathrm{~min} ; p>0.7)$. These results support our previous in vitro $\mathrm{O}_{2}$ interference studies (Lowry et al., 1994b) and confirm that Pt/PPD/GOx sensors are not affected by changes in $\mathrm{O}_{2}$ over physiologically relevant concentration ranges for the brain. A similar lack of $\mathrm{O}_{2}$ interference has also been observed by other groups; Asai et al. (1996) have used glutamate oxidase and a dialysis electrode incorporating a PPD coated $\mathrm{Pt}$ wire to monitor brain extracellular glutamate during acute ischemia and found that the sensor operates reliably despite the lack of $\mathrm{O}_{2}$ around the dialysis electrode and Garguilo and Michael (1994) have found that the availability of $\mathrm{O}_{2}$ in brain ECF is sufficient for
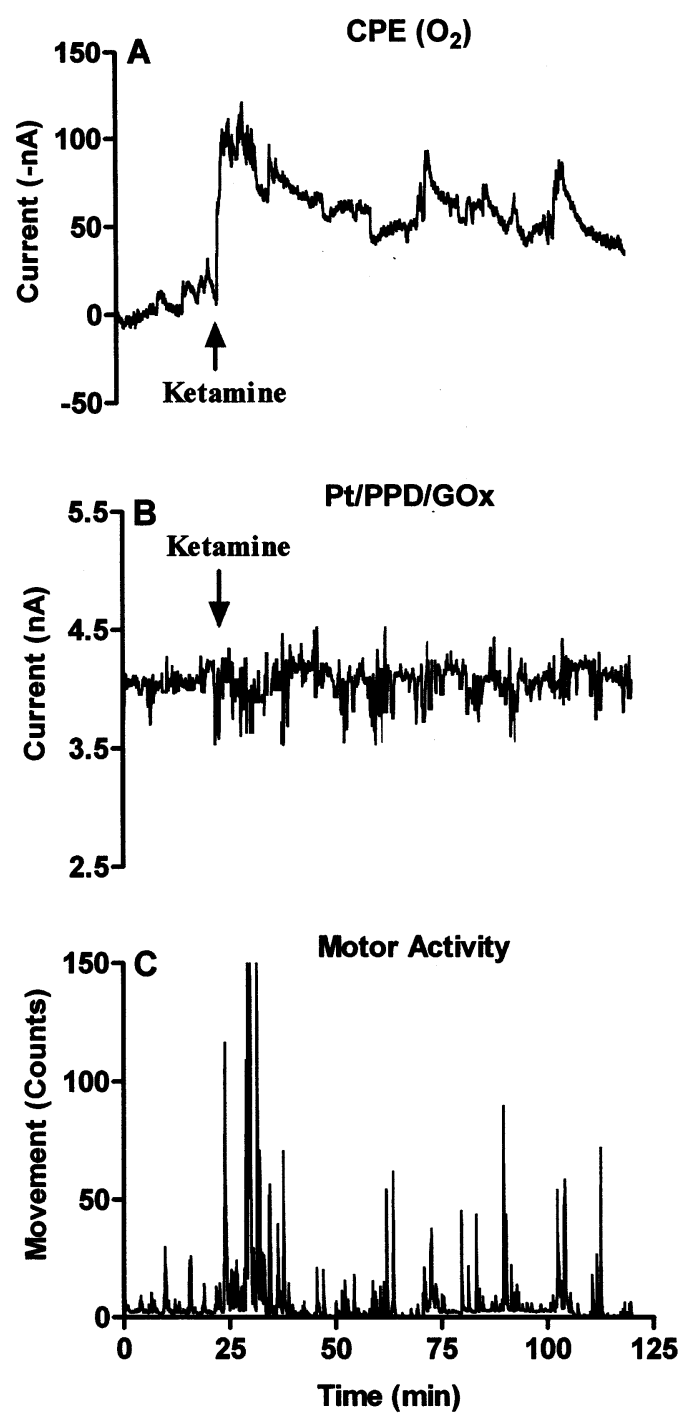

Fig. 3. An example of the effect of a subanaesthetic intraperitoneal injection of ketamine $(50 \mathrm{mg} / \mathrm{kg})$ on the carbon paste electrode (CPE) $\mathrm{O}_{2}$ (A) and Pt/PPD/GOx (B) signals recorded simultaneously in the striatum of freely-moving rats with bilaterally implanted sensors. The tissue $\mathrm{O}_{2}$ was monitored using differential pulse amperometry and the background current has been subtracted. Also shown is a record of the motor activity $(\mathrm{C})$ recorded over the same period with a radarbased doppler shift motion detector. See Section 3.4. 
reliable operation of choline sensors based on the immobilisation of choline oxidase onto carbon fiber microelectrodes.

\subsection{Effect of ascorbic acid on biosensor response in vivo}

The principal endogenous electroactive interferent affecting the application of electrochemical sensors in brain $\mathrm{ECF}$ is the reducing agent $\mathrm{AA}$, which exists in anionic form at physiological pH (Youngblood, 1989) and whose extracellular concentration has been estimated at $\approx 500 \mu \mathrm{M}$ (Miele and Fillenz, 1996). In order to determine whether AA in brain ECF would interfere with glucose detection using a $\mathrm{Pt} / \mathrm{PPD} / \mathrm{GOx}$ sensor we simultaneously monitored AA concentration in the left striatum with a CPE at a constant potential of +250 $\mathrm{mV}$ and the Pt/PPD/GOx current in the right striatum following injection of a high dose $(2 \mathrm{~g} / \mathrm{kg}$, i.p.) of AA. The AA current increased from a mean baseline value of $2.4 \pm 0.7$ to $5.2 \pm 1.0 \mathrm{nA}(n=5 ; p<0.04) 11 \pm 3 \mathrm{~min}$ after injection. Since techniques such as CPA which have long sampling times cause a significant depletion of extracellular AA (Rice and Nicholson, 1995), it is not possible to quantify the latter increase in current in terms of concentration, however, this increase (for i.p. injection) is substantially greater than the increases observed using CPA during normal and stimulated physiological activity (Boutelle et al., 1989). There was no overall change in the response of the $\mathrm{Pt} / \mathrm{PPD} / \mathrm{GOx}$ sensors during the same period: $3.1 \pm 0.9 \mathrm{nA}$ to $3.0 \pm$ $0.9(n=5 ; p>0.25)$, clearly demonstrating that the observed glucose signal is not affected by changes in AA in vivo, even those greater than observed during behavioural activation (Fig. 4).

We also monitored extracellular AA during the injection of subanaesthetic doses of ketamine using the DPA technique, which, in addition to detecting changes in $\mathrm{O}_{2}$, also enables simultaneous monitoring of AA in vivo (Lowry et al., 1996). Injection of $50 \mathrm{mg} / \mathrm{kg}$ ketamine i.p., which produced no change in the $\mathrm{Pt} / \mathrm{PPD} / \mathrm{GOx}$ signal (see above), caused a maximum increase in AA of $6.8 \pm 1.0 \mathrm{nA}(n=3 ; p<0.19)$ above baseline at $8.4 \pm 3.5 \mathrm{~min}$ following injection (see inset Fig. 4). Using post in vivo calibrations this represents an increase in AA concentration of $164 \pm 23 \mu \mathrm{M}$ representing an $\approx 30 \%$ increase in ECF levels assuming the DPA technique causes minimum depletion as it is a fast sampling technique (Lowry et al., 1997).

\subsection{Stability of biosensor in vivo}

The direct contact of biosensors with biological samples can lead to a decrease in sensitivity due to surface fouling by proteins and other biomolecules. This decrease in sensitivity generally varies between 20 and

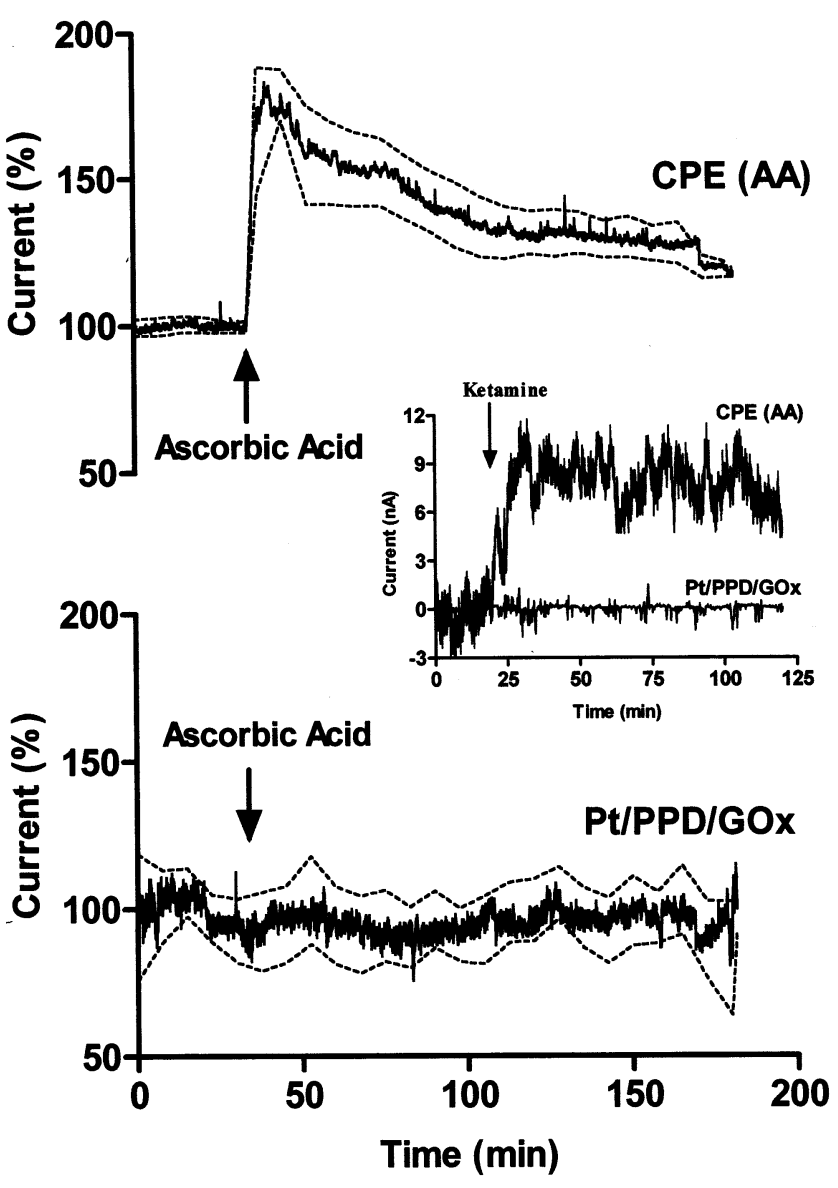

Fig. 4. The effect of intraperitoneal injection of ascorbic acid (AA; 2 $\mathrm{ml}, 2 \mathrm{~g} / \mathrm{kg}$ ) on the amperometric response of carbon paste (CPE; top) and $\mathrm{Pt} / \mathrm{PPD} / \mathrm{GOx}$ (bottom) sensors implanted bilaterally in the striatum of freely-moving rats. The CPEs monitored AA at a constant potential of $+250 \mathrm{mV}$. Data $(n=5)$ are normalised with the basal level before injection taken as $100 \%$. The hashed lines represent the SEM which is plotted at $8 \mathrm{~min}$ intervals for clarity. Changes in response expressed in nanoamperes of current are given in the text. Inset: Example of the effect of a subanaesthetic injection of ketamine $(50 \mathrm{mg} / \mathrm{kg}$, i.p.) on the CPE AA and Pt/PPD/GOx signals recorded simultaneously in rat striatum. AA was monitored using differential pulse amperometry. The baseline currents for both signals have been subtracted. See Section 3.5.

$50 \%$ and occurs over several hours exposure to brain tissue (Garguilo and Michael, 1994; Hu et al., 1994). Although previous in vitro studies have shown that $\mathrm{Pt} / \mathrm{PPD} / \mathrm{GOx}$ sensors are virtually free from both protein and lipid fouling (Lowry and O'Neill, 1994) we carried out an additional in vitro conditioning of the sensors prior to implantation (see Section 2.4), similar to the preconditioning procedure used by Hill and coworkers to improve the stability of ferrocene-mediated glucose biosensors (Cass et al., 1984). The mean baseline current recorded with preconditioned $\mathrm{Pt} / \mathrm{PPD} /$ GOx sensors implanted in the striatum of freely-moving animals showed no significant variation $(p>0.88$, twoway ANOVA; $n=6$ ) over a successive 5 day period from day 0 (ca. $1 \mathrm{~h}$ following recovery from surgical 
anaesthesia) to day $4: 15.6 \pm 3.5 \mathrm{nA}$ (day 0$) ; 16.2 \pm 2.2$ $\mathrm{nA}$ (day 1); $16.1 \pm 3.6 \mathrm{nA}$ (day 2); $14.0 \pm 2.7 \mathrm{nA}$ (day 3$)$ and $13.2 \pm 2.4 \mathrm{nA}$ (day 4). This represents a statistically insignificant change in sensitivity after 5 days recording and clearly demonstrates that the combination of nonfouling properties of the PPD coating and in vitro conditioning of the enzyme and $\mathrm{Pt}$ surface (via prolonged enzymatic turnover and $\mathrm{H}_{2} \mathrm{O}_{2}$ oxidation) ensures minimal loss of sensitivity of these biosensors after implantation and a resultant stable glucose signal in vivo. Using glucose calibration data suggests that this baseline level corresponds to a concentration of $488 \pm$ $84 \mu \mathrm{M}(n=6)$.

\section{Conclusions}

These results demonstrate that our Pt/PPD/GOx sensor responds to changing concentrations of glucose in the extracellular compartment of the brain, is unaffected by changes in the concentration of both $\mathrm{O}_{2}$ and $\mathrm{AA}$ and is stable after implantation, clearly demonstrating reliable glucose monitoring in vivo in freelymoving animals.

\section{Acknowledgements}

J.P.L. is a Marie Curie Fellow (European Commission Grant Nos. ERB CHB ICT94 1353 and ERB FMB ICT96 1319). MM acknowledges the CNR (Italy) for a visiting research fellowship to UCD. RON acknowledges Forbairt for grants under the Scientific Research Programme (Grant Nos. SC/92/304 and SC/ 94/304).

\section{References}

Albery WJ, Boutelle MG, Galley PT. The dialysis electrode-a new method for in vivo monitoring. J Chem Soc Chem Comun 1992;12:900-1.

Asai S, Iribe Y, Kohno T, Ishikawa K. Real time monitoring of biphasic glutamate release using dialysis electrode in rat acute brain ischemia. Neuroreport 1996;7:1092-6.

Bartlett PN, Birkin PR. A microelectrochemical enzyme transistor responsive to glucose. Anal Chem 1994;66:1552-9.

Berners MOM. Development of enzyme based sensors for use in neurochemistry, D Phil Thesis. Oxford: University of Oxford, 1996:73.

Bhattacharya SK, Saraswati M. Effect of intracerebroventricularly administered insulin on brain monoamines and acetylcholine in euglycaemic and alloxan-induced hypoglycemic rats. Ind J Exp Biol 1991;29:1095-100.

Bourdillon C, Thomas V, Thomas D. Electrochemical study of D-glucose oxidase autoinactivation. Enzyme Microb Technol 1982;4:175-80.

Boutelle MG, Stanford C, Fillenz M, Albery WJ, Bartlett PN. An amperometric enzyme electrode for monitoring brain glucose in the freely moving rat. Neurosci Lett 1986;72:283-8.
Boutelle MG, Svensson L, Fillenz M. Rapid changes in striatal ascorbate in response to tail-pinch monitored by constant potential voltammetry. Neuroscience 1989;30:11-7.

Cass AEG, Davis G, Francis GD, et al. Ferrocene-mediated enzyme electrode for amperometric determination of glucose. Anal Chem 1984;56:667-71.

Chen Z, Steger RW. Plasma microdialysis: A technique for continuous plasma sampling in freely moving rats. J Pharmacol Toxicol Methods 1993;29:111-8.

Clark LC Jr, Lyons C. Electrode systems for continuous monitoring of cardiovascular surgery. Ann NY Acad Sci 1962;102:29-45.

de Boer J, Damsma G, Fibiger HC, Timmerman N, deVries JB, Westerlink BHC. Dopaminergic-cholinergic interactions in the striatum: The critical significance of $\mathrm{Ca}^{2+}$ concentration in brain microdialysis. Naunyn-Schmiedeberg's Arch Pharmacol 1990;342:528-34.

Demestre M, Boutelle MG, Fillenz M. Stimulated release of lactate in freely moving rats is depenedent on the uptake of glutamate. J Physiol (London) 1997;499:825-32.

DiMattio J, Streitman J. In vivo comparative study of ascorbic acid and glucose transport into cerebrospinal fluid of the rat. Ann NY Acad Sci 1988;529:67-9.

Dong SJ. Surface modification of electrodes for amperometric biosensors in analytical chemistry. Anal Sci 1994;10:175-7.

Feng Z-C, Roberts EL, Sick TJ, Rosenthal M. Depth profile of local oxygen tension and blood flow in rat cerebral cortex, white matter and hippocampus. Brain Res 1988;445:280-8.

Fillenz M, Lowry JP. The relation between local cerebral blood flow and extracellular glucose concentration in rat striatum. Exp Physiol, in press.

Fortier G, Brassard E, Belanger D. Optimization of a polypyrrole glucose oxidase biosensor. Biosens Bioelectron 1990;5:473-90.

Fray AE, Forsyth RJ, Boutelle MG, Fillenz M. The mechanisms controlling physiologically stimulated changes in rat brain glucose and lactate: a microdialysis study. J Physiol (London) 1996;496:49-57.

Friedemann MN, Robinson SW, Gerhardt GA. $o$-Phenylenediamine modified carbon fiber electrodes for the detection of nitric oxide. Anal Chem 1996;68:2621-8.

Garguilo MG, Michael AC. An enzyme-modified microelectrode that detects choline injected locally into brain tissue. J Am Chem Soc 1993;115:12218-9.

Garguilo MG, Michael AC. Quantitation of chloine in the extracellular fluid of brain tissue with amperometric microsensors. Anal Chem 1994;66:2621-9.

$\mathrm{Hu}$ Y, Mitchell KM, Albahadily FN, Michaelis EK, Wilson GS. Direct measurement of glutamate release in the brain using a dual enzyme-based electrochemical sensor. Brain Res 1994;659:117-25.

Jantzen J. Cerebral protection and ketamine. Anaesthesist 1994;43:S41-7.

Lahti AC, Holcomb HH, Medoff DR, Tamminga CA. Ketamine activates psychosis and alters limbic blood flow in schizophrenia. Neuroreport 1995;6:869-72.

Lowry JP, McAteer K, El Atrash SS, Duff A, O’Neill RD. Characterisation of glucose oxidase-modified poly(phenylenediamine)coated electrodes in vitro and in vivo: Homogeneous interference by ascorbic acid in hydrogen peroxide detection. Anal Chem 1994a;66:1754-61.

Lowry JP, McAteer K, El Atrash SS, O’Neill RD. Efficient glucose detection in anaerobic solutions using an enzyme-modified electrode designed to detect $\mathrm{H}_{2} \mathrm{O}_{2}$ : Implications for biomedical applications. J Chem Soc Chem Comun 1994b;21:2483-4.

Lowry JP, O'Neill RD. Partial characterization in vitro of glucose oxidase modified poly(phenylenediamine)-coated electrodes for neurochemical analysis in vivo. Electroanalysis 1994;6:369-79.

Lowry JP, Boutelle MG, O'Neill RD, Fillenz M. Characterisation of carbon paste electrodes in vitro for simultaneous amperometric measurement of changes in oxygen and ascorbic acid concentrations in vivo. Analyst 1996;121:761-6. 
Lowry JP, Fillenz M. In vivo glucose measurements in rat striatum with an implanted sensor. J Neurochem (Abstr) 1996;66(Suppl 2):S92A.

Lowry JP, Boutelle MG, Fillenz M. Measurement of brain tissue oxygen at a carbon paste electrode can serve as an index of increases in regional cerebral blood flow. J Neurosci Methods 1997;71:177-82.

Lowry JP, Fillenz M. Evidence for uncoupling of oxygen and glucose utilisation during neuronal activation in rat striatum. J Physiol (London) 1997;498:497-501.

Malitesta C, Palmisano F, Torsi L, Zambonin PG. Glucose fast-response amperometric sensor based on glucose oxidase immobilised in an electropolymerized poly (o-phenylenediamine) film. Anal Chem 1990;62:2735-40.

Miele M, Fillenz M. In vivo determination of extracellular brain ascorbate. J Neurosci Methods 1996;70:15-7.

Morton DB, Griffiths PHM. Guidelines on the recognition of pain and discomfort in experimental animals and an hypothesis for assessment. Vet Rec 1985;116:431-6.

Netchiporouk LI, Shram NF, Jaffrezic-Renault N, Martelet C, Cespuglio R. In vivo brain glucose measurements: Differential normal pulse voltarnmetry with enzyme-modified carbon fibre microelectrodes. Anal Chem 1996;68:4358-64.

O'Neill RD. Sensor-tissue interactions in neurochemical analysis with carbon paste electrodes in vivo. Analyst 1993;118:433-8.

O'Neill RD. Microvoltammetric techniques and sensors for monitoring neurochemical dynamics in vivo. A review. Analyst 1994;119:767-79.

O'Neill RD, Grunewald RA, Fillenz M, Albery WJ. Linear sweep voltammetry with carbon paste electrodes in rat striatum. Neuroscience 1982;7:1945-54.

Pantano P, Kuhr WG. Enzyme-modified microelectrodes for in vivo neurochemical measurements. Electroanalysis 1995;7:405-16.

Paxinos G, Watson C. The Rat Brain in Stereotaxic Coordinates, Sydney: Academic Press, 1986.
Pfeiffer EF, Kerner W. Implantable Glucose Sensors-The State of the Art. New York: Thieme Medical Publishers, 1988.

Rice ME, Nicholson C. Diffusion and ion shifts in the brain extracellular microenvironment and their relevance for voltammetric measurements: The brain is not a beaker: In vitro versus in vivo voltammetry. In: Boulton AA, Baker GB, Adams RN, editors. Voltamrnetric Methods in Brain Systems, Neuromethods, vol 27. New Jersey: Humana Press, 1995:51-53.

Sasso SV, Pierce RJ, Walla R, Yacynych AM. Electropolymerized 1,2 diaminobenzene as a means to prevent interferences and fouling and to stabilize immobilised enzyme in electrochemical biosensors. Anal Chem 1990;62:1111-7.

Shaolin M, Huaiguo X, Bidong Q. Bioelectrochemical response of the polyaniline glucose oxidase electrode. J Electroanal Chem Interfacial Electrochem 1991;304:7-16.

Silver IA, Ereciñska M. Extracellular glucose concentration in mammalian brain: Continuous monitoring of changes during increased neuronal activity and upon limitation in oxygen supply in normo-, hypo- and hyperglycemic animals. J Neurosci 1994;14:5068-76.

Stryer L. Biochemisty, New York: WH Freeman, 1988:458.

Turner APF, Karube I, Wilson GS, editors. Biosensors: Fundamentals and Applications. New York: Oxford University Press, 1987.

Wilson R, Turner APF. Glucose oxidase: An ideal enzyme. Biosens Bioelectron 1992;7:165-85.

Wolfensohn S, Lloyd M. Handbook of Laboratory Animal Management and Welfare, Oxford: Oxford University Press, 1994.

Youngblood MP. Kinetics of electron-transfer reactions of hydroquinones and ascorbic acid with 1-phenyl-3-pyrazolidone radicals. J Am Chem Soc 1989;111:1843-9.

Zhang YN, Wilson GS. In vitro and in vivo evaluation of oxygen effects on a glucose oxidase based implantable glucose sensor. Anal Chem Acta 1993;281:513-20.

Zimmerman JB, Wightman RM. Simultaneous electrochemical measurement of oxygen and dopamine in vivo. Anal Chem 1991;63:24-8. 